\title{
BMJ Open Identifying priority policy issues and health system research questions associated with recovery outcomes for burns survivors in India: a qualitative inquiry
}

\author{
Jagnoor Jagnoor, ${ }^{1,2}$ Sheree Bekker, ${ }^{3}$ Shobha Chamania, ${ }^{4}$ Tom Potokar, ${ }^{5}$ \\ Rebecca Ivers ${ }^{2}$
}

To cite: Jagnoor J, Bekker S, Chamania S, et al. Identifying priority policy issues and health system research questions associated with recovery outcomes for burns survivors in India: a qualitative inquiry. BMJ Open 2018;8:e020045. doi:10.1136/ bmjopen-2017-020045

- Prepublication history and additional material for this paper are available online. To view these files, please visit the journal online (http://dx.doi. org/10.1136/bmjopen-2017020045).

Received 12 October 2017 Revised 6 February 2018 Accepted 7 February 2018
Check for updates

For numbered affiliations see end of article.

Correspondence to Dr Jagnoor Jagnoor; jjagnoor@george.org.au

\section{ABSTRACT}

Objectives This study aimed to identify priority policy issues and health system research questions associated with recovery outcomes for burns survivors in India. Design Qualitative inquiry; data were collected through semistructured in-depth interviews and focus group discussions.

Setting Nine sites in urban and rural settings across India, through primary, secondary and tertiary health facilities.

Participants Healthcare providers, key informants, burns survivors and/or their carers.

Results Participants acknowledged the challenges of burns care and recovery, and identified the need for prolonged rehabilitation. Challenges identified included poor communication between healthcare providers and survivors, limited rehabilitation services, difficulties with transportation to health facility and high cost associated with burns care. Burns survivors and healthcare providers identified the stigma attached with burns as the biggest challenge within the healthcare system, as well as in the community. Systems barriers (eg, limited infrastructure and human resources), lack of economic and social support, and poor understanding of recovery and rehabilitation were identified as major barriers to recovery. Conclusions Though further research is needed for addressing gaps in data, strengthening of health systems can enable providers to address issues such as developing/providing, protocols, capacity building, effective coordination between key organisations and referral networks.

\section{INTRODUCTION}

Burns contribute significantly to the global burden of death and disability, resulting in at least 265000 deaths annually and are one of the leading causes of disability-adjusted lifeyears in low-and-middle-income countries (LMICs).${ }^{1-3}$ Burns consistently rank among the top causes of morbidity and mortality globally; however. have never received sufficient attention in global or national policy
Strengths and limitations of this study

- This research will inform the development of acceptable models of burns care from consumer, provider and health manger perspective.

- Participants from diverse backgrounds and a number of settings were involved in this research, providing a broad range of perspectives.

- Interviews and focus group discussions were undertaken in both Hindi and Marathi, with two levels of quality check performed to ensure highquality translation.

- The outcomes of this study reflect the experiences and beliefs of the participants involved, potentially limiting generalisability.

initiatives as they do not neatly fit under any single Millennium Development Goal and are not captured in the Sustainable Developmental Goals. ${ }^{4} 5$ WHO has, therefore, described burns as the 'forgotten global public health crisis'.

In high-income countries, the incidence of burns has decreased and survival rates and recovery have improved, while in LMICs the incidence remains high and survival rates are poor. ${ }^{6}$ Burns are a striking example of the inequity of injury as the burden is borne primarily by poor people in poor countries where prevention programmes are uncommon and the quality of acute care is inconsistent at best. ${ }^{6}$ Over half of all burns-related deaths in the world are in the WHO South East Asia region, where India has the largest burden with $>1000000$ people moderately or severely burnt every year, resulting in between 92000 and 163000 deaths. ${ }^{7}$ Further, it is estimated that 106000 of these deaths occur in women, aged between 15 and 34 years. $^{7}$ This age-sex distribution has been 
consistent across multiple hospital-based studies, and the ratio of fire-related deaths of women to men is $3: 1{ }^{7}$ Prevention efforts pose challenges particularly in the context of intent of the injury among women as self-immolation and domestic violence are common contributors to burn injury. ${ }^{8}$

Few patients with burns in LMICs receive appropriate first aid or immediate acute care, compounded by limited access to rehabilitation. In addition to physical disabilities, this often results in further complications such as anxiety, depression and post-traumatic stress disorder, often leading the patient to the conclusion that little or nothing can be done for recovery. ${ }^{9}$ As a result, burns survivors become emotionally overwhelmed and typically withdraw. Unfortunately, this lack of activity exacerbates secondary problems such as contractures, thereby heightening the survivor's disability. ${ }^{10} 11$

The high burden of burns in India is known, and the challenges in prevention and care are recognised. However, there is poor understanding of the factors and interrelationships for planning effective measures for improving outcomes in burns survivors in India. The aim of this study was, therefore, to identify priority policy issues and health system research questions associated with recovery outcomes for burns survivors in India.

\section{METHODS}

This study was informed by systems thinking, which views health in the broader dynamic social and economic context, recognising patterns and interrelationships with the aim of structuring those interrelationships in more effective, efficient ways. ${ }^{12} 13$

The research underpinned by systems thinking used participatory research for identifying priority areas for research, health system and policy aims to co-design interventions for the same. This study reports on the second phase of data collection in the participatory action research model. It informs on the networks, views health in the broader dynamic social and economic context, recognising patterns and interrelationships with the aim of structuring those interrelationships in more effective, efficient ways. ${ }^{12} 13$

Qualitative inquiry, ${ }^{14}$ consisting of interviews and focus group discussions (FGDs), was used to identify the needs of patients and carers within the burns healthcare context, as well as the experiences of healthcare providers and key informants, to develop acceptable approaches to address these needs in this setting. The rich diagram illustrates underlying mental models used during analysis. Rich diagrams (the precursor to Causal Loop Diagrams) are typically prototypes used to illustrate feedback and interactions among health system actors within a complex adaptive system. ${ }^{12}{ }^{13}$ For this study, we present the initial identification and interpretation of the setting and interrelationship of factors that emerged in the context of burns care, influencing recovery outcomes in India.

\section{Setting}

India has a decentralised public healthcare system, run largely by its 29 states and 7 territories. The central government's only constitutional mandate is to oversee medical education and collect infectious diseases statistics. In principle, coverage of health services in India is universal and available to all citizens under the tax-financed public system. Free primary care is provided by the public sector, supplemented by strategic purchase of secondary and tertiary care services from both the public and private sectors, which is the main financing approach. ${ }^{15}$

A National Programme for Prevention and Management of Burn Injuries was included in India's 12th Five Year Plan in 2012. ${ }^{16}$ Increased resource contribution from the central and state governments was proposed. The programme commitment from policy makers holds promising opportunities for development of effective burns care system in India. ${ }^{16}$

This study was carried out across nine different sites in India, between June and October 2016. The aim was to include all primary and important secondary stakeholders at the meso and micro levels. A range of settings including urban and rural, health facilities ranging from tertiary to primary healthcare centres, private, charitable and public facilities and state settings using social development index as the primary indicator were included.

\section{Participants}

Participants in this study included healthcare providers, burns survivors, caregivers, neighbours/community, non-governmental organisations involved in rehabilitation, legal aid, workplaces and key personnel in health service implementation. Children were not included as participants; however, carers of child burn survivors were invited to participate. A purposive snowball sampling method was used whereby respondents were asked to suggest other potential stakeholders to be interviewed. This approach assisted with identifying and defining the boundaries of the network. Participant information is presented in tables 1 and 2, categorised as three main groups (patients and carers, healthcare providers, key informants).

\section{Data collection}

Prior consultation included in-depth interviews with healthcare providers only, and the key finding was the heterogeneity of healthcare services. The findings from the consultation helped identify key stakeholder groups and the breadth of healthcare settings. This paper presents the second round of data collection. We developed the interview and FGD guides based on a narrative synthesis of rehabilitation practices and recovery outcomes in burns survivors, and the initial stakeholder consultation. Before the interview or FGD, participants were provided standardised verbal and written information about the purpose of the research work, all data collection was face-to-face. 
Table 1 Study participants: stakeholders in burns care in India (healthcare providers and key informants)

\begin{tabular}{llllc}
\hline Participant & Healthcare providers & $\begin{array}{l}\text { Interview or focus } \\
\text { group discussion }\end{array}$ & Type of facility & $\begin{array}{l}\text { Years working in burns } \\
\text { care/area }\end{array}$ \\
\hline 1 & Social worker and psychologist & Interview & Charitable & 8 \\
\hline 2 & Physiotherapist & Interview & Charitable & 6 \\
3 & General surgeon & Interview & Charitable & 18 \\
4 & Physiotherapist & Interview & Public & 5 \\
\hline 5 & Nutritionist & Interview & Charitable & 4 \\
\hline 6 & Occupational therapist & Interview & Charitable & 5 \\
\hline 7 & Nutritionist & Interview & Private & 3 \\
\hline 8 & Plastic surgeon & Interview & Charitable & 4 \\
\hline 9 & Prosthetist & Interview & Private & 4 \\
\hline 10 & Resident doctor & Interview & Private & 4 \\
\hline 11 & Head nurse & Interview & Public & 12 \\
\hline 12 & Nurse & Interview & Public & 4 \\
13 & General surgeon & Interview & Public \\
\hline 14 & Emergency medical officer & Interview & Public & 14 \\
\hline 15 & General surgeon & Interview & Private \\
\hline 16 & General surgeon & Interview & Public & 11 \\
\hline & Key informants & & & 20 \\
\hline 17 & Paralegal & Interview & - & 7 \\
\hline 18 & State nodal officer & Interview & - \\
\hline
\end{tabular}

For this study, semistructured in-depth interviews and FGDs at burns care services in India were undertaken to explore the participants' own framework of meaning; for example, what a good outcome means to a health professional and the injured person. Written consent from participants was sought prior to each interview or FGD. The interviewer used the interview or FGD guide (online supplementary appendix 1 ) covering a range of social, economic, cultural, psychological and environmental factors influencing burns care. Beliefs about

Table 2 Study participants: stakeholders in burns care in India (patients and carers)

\begin{tabular}{|c|c|c|c|c|}
\hline & Patients & Gender & $\begin{array}{l}\text { Interview or focus group } \\
\text { discussion }\end{array}$ & Mechanism of injury \\
\hline $20^{*}$ & Patient & Female & $\begin{array}{l}\text { Focus group } \\
\text { (nine participants of survivor group) }\end{array}$ & Mixed/unknown \\
\hline 21 & Patient & Male & Interview & Flame burn \\
\hline 22 & Patient & Female & Interview & Self-immolation \\
\hline 23 & Patient & Male & Interview & Occupational-factory plastic \\
\hline 24 & Patient & Male & Interview & Occupational-gas service power station \\
\hline 25 & Patient & Male & Interview & Kerosene stove burn \\
\hline 26 & Patient & Male & Interview & $\begin{array}{l}\text { Occupational-apprentice at electrical } \\
\text { board }\end{array}$ \\
\hline \multirow[t]{2}{*}{27} & Patient & Male & Interview & Occupational-contractor \\
\hline & Carers & & & \\
\hline 28 & Carer & Female & Interview & Aunt of paediatric burn survivor \\
\hline 29 & Carer & Male & Interview & Father of child who fell into fire furnace \\
\hline
\end{tabular}

*Focus group discussion was all female participants and purposively male participants dominated the sample covering broader aspects other than gender and domestic burns. 
practices, perceptions of their benefits and harms, effects of these practices and decision-making processes in health facilities, families and communities related to burns care were also explored.

Interviews lasted between 40 and $60 \mathrm{~min}$ in locations acceptable to the interviewees. Interviews were conducted in Hindi and Marathi, recorded, translated and transcribed in English. Handwritten field notes were made. To minimise data loss, interviews were jointly translated and transcribed by the interviewing researcher and the translator, and a member of the research team checked the translated transcripts with the Hindi and Marathi transcripts. Interviews ceased when saturation of meaning was considered to have occurred. ${ }^{17}$

The FGD was undertaken with nine burns survivors, caregivers and community workers. Participants were identified by the researchers in advance through patient support groups, healthcare providers and community workers. Participants were invited for discussion at a safe location in the community.

\section{Data analysis}

Transcripts were imported into NVivo qualitative data analysis software V. 11 (QSR International, 2015). Content analysis was applied to the transcripts whereby overarching themes were initially developed, informed by the understandings of a systems thinking perspective. Thereafter, deductive thematic coding of the data was undertaken. NVivo was used to arrange the text according to codes and manage the codes in the interpretive phase.

Through the qualitative data analysis, a rich diagram (figure 1) was developed using the software package Vensim PLE (Ventana Systems, 2015). For this study, the purpose of the diagram was to assist in the identification and interpretation of the context, components and outcomes that emerged in the context of burns care.

\section{RESULTS}

The interviews provided rich data, which described participant behaviour in relation to their service seeking, adherence to treatment and the broader sociocultural influencers throughout their burns care journey in the healthcare system.

Four themes were coded across all stakeholder groups, and resultant emerging threads were similar and interconnected. Quotes demonstrating these themes are

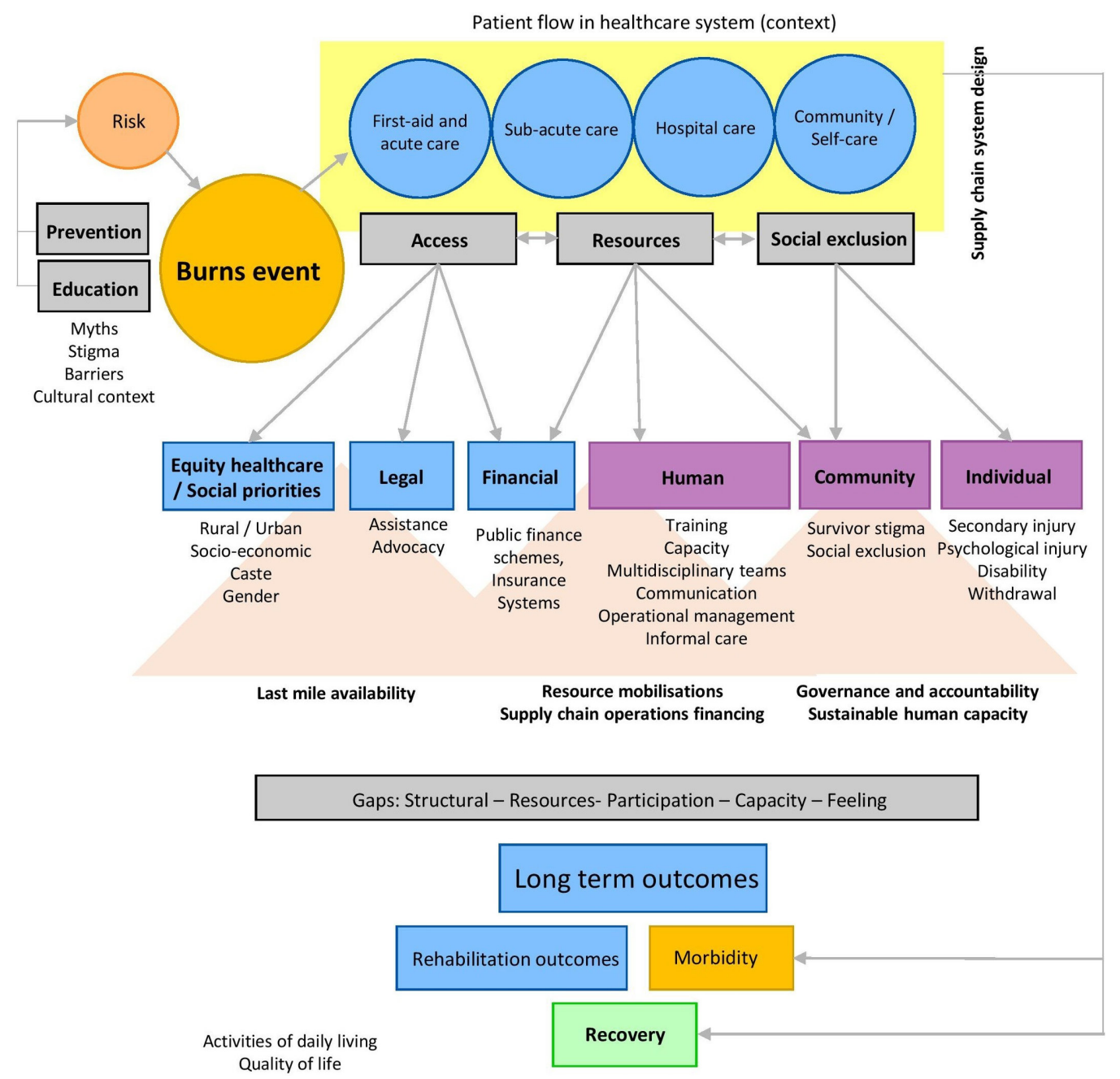

Figure 1 System characteristics impacting recovery outcomes for burns in India. 
presented in table 3. The rich diagram (figure 1) was developed out of the background understanding of this research and filled with emerging themes from the coding process. It was further informed by theory underpinning health systems strengthening to ensure effective health supply chains. ${ }^{18}$

\section{DISCUSSION}

The aim of this study was to identify priority policy issues and health system research questions associated with recovery outcomes for burns survivors in India. To contextualise our findings, we first present a discussion of the findings and how this was used to inform the development of the rich diagram (figure 1). We integrate this research into the wider context of burns, policy and health systems in India. Finally, this section will present considerations and research questions that emerged from this research.

\section{Theme 1: shared tasks—care and rehabilitation}

This theme articulates with the quotes presented in table 3 , theme 1 , and figure 1 section on patient flow in the healthcare system.

Participants from all three groups (patients and carers, healthcare providers, key informants) described the patient journey from the burns event through the healthcare system (figure 1-patient flow in the healthcare system). Limited resources were acknowledged but not seen as a major concern, with responsibilities shared between carers and health service providers. Time restraints and a shortage of health professionals willing to engage with burns care were raised. Participants, families and other carers were identified as playing an integral role as caregivers or attendees throughout the process of care. All groups raised the scope for their better inclusion in the care and rehabilitation process (table 2, theme 1).

Patients and carers expressed they experienced a gap in communication with healthcare providers, with many reporting not having been provided sufficient information about the care needed, and thus the level/type of care that they were able to provide in turn. There appeared to be a disconnect in healthcare provider perceptions around what information they provide with regards to rehabilitation education and practices, and this was particularly evident for information around burns dressings, dietary needs and posthospital physiotherapy, as well as resultant issues such as contractures.

Burns survivors and carers expressed frustration negotiating the complex, resource-intensive care system, with high out-of-pocket costs, access (transportation) issues and poor understanding of recovery. Patients and carers appear to trust healthcare providers; however, they also felt that they could not query healthcare providers around issues of care due to insufficient knowledge, indicating a potential cultural/education barrier. This suggests that there is scope for better processes around patient and carer education. One patient in particular suggested that people-centred care within the health system would be empowering (table 3 , theme 1 ).

\section{Theme 2: coordinated—multidisciplinary care}

This theme articulates with table 3 , theme 2 , and figure 1 section on patient flow in the healthcare system, and overall strengthening health systems.

Stakeholder roles were varied, and the need for strong, cohesive multidisciplinary teams was well-recognised. Healthcare providers stressed that working in a multidisciplinary team is extremely important to the success of providing optimal care (table 3, theme 2). Healthcare providers often referred to burns care as a 'not rewarding' area to work in as recovery outcomes are often poor due to barriers, multiple levels of care and lack of multidisciplinary coordinated care.

The shortage of nursing staff and overall workforce (human resources) in burns care was evident. These healthcare providers expressed a great need for not only training but also retention of nurses (and other key hospital staff). As such, caregivers and attendants are regarded an integral part of the multidisciplinary team, which poses a question around better processes for their inclusion in the healthcare system. It is recognised that the quality of such assistance is variable, but also that better inclusion to this end would be valuable. This connects with the issues emerging in theme 1 around shared tasks in care and rehabilitation. Similar challenges are also experienced in rural and remote communities in high-income context. ${ }^{19}$

The key informants stressed the importance of legal and financial assistance, particularly for patients with burns who have experienced gender-based violence (table 3, theme 2). The findings integrate with work from Morgan et $a l,{ }^{20}$ who emphasise that health systems are not gender neutral; gender being a key social stratifier affecting health system needs, experiences and outcomes. Gender influences how people interact dynamically in complex, multifaceted and context-specific ways, reflecting varying interests, values and power, and therefore is at the core of health and health systems research.

\section{Theme 3: community, access and health delivery systems}

This theme articulates with table 3 , theme 3 , and figure 1 sections on the patient flow in the healthcare system, strengthening health systems, as well as the gaps elicited.

A major issue with hospital admissions process was patients moving between hospitals in the very early stages of their care (often taking days before proper care is received), as described by patients and their carers (table 3, theme 3). This intersects with known negative outcomes for recovery when adequate care is not received timeously. Difficulties with transportation to health facilities compounded this lack of access to healthcare in the acute phase of care.

Satellite centres or community-based rehabilitation for follow-up of discharged patients were regarded as essential as patients often do not return to hospital due 


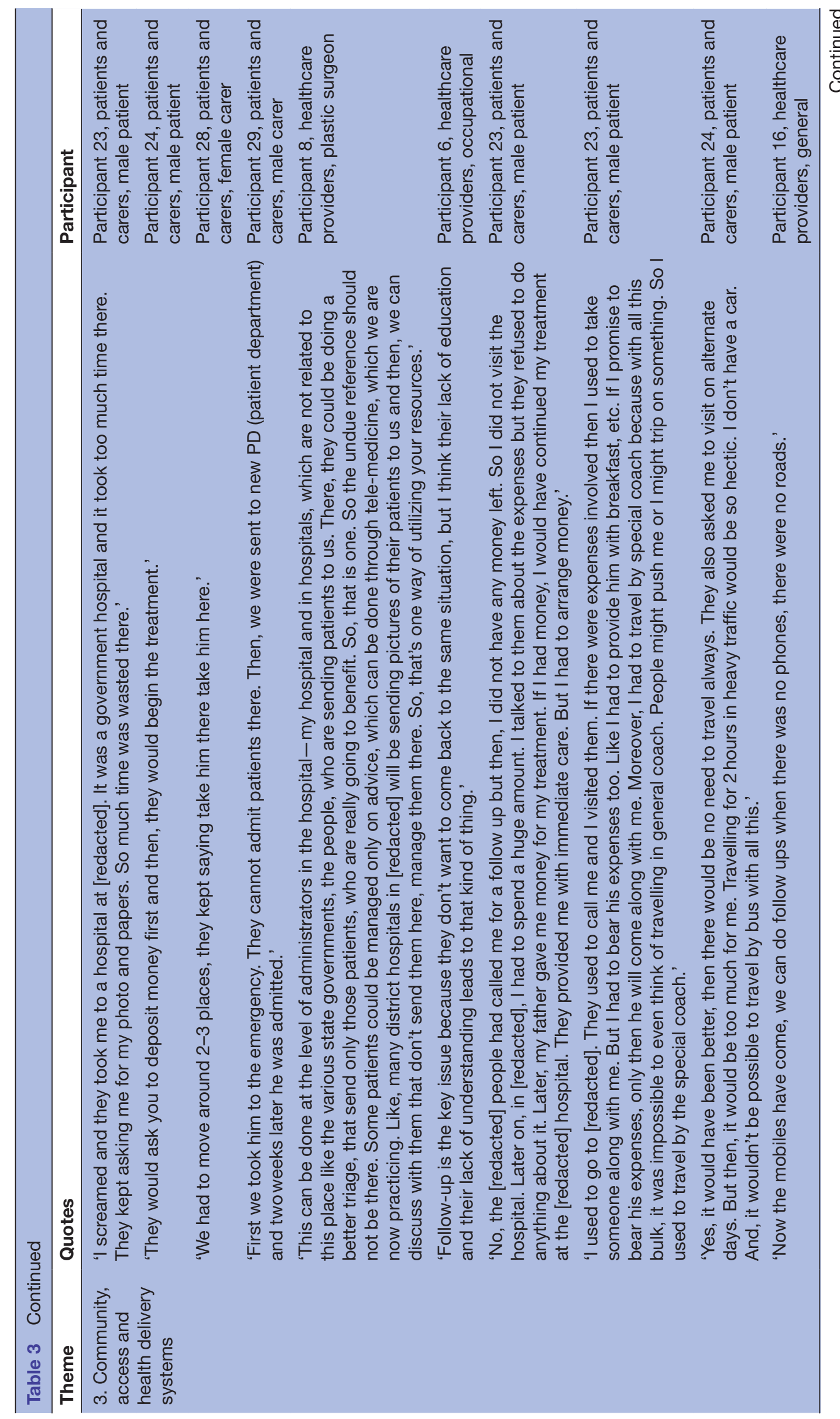




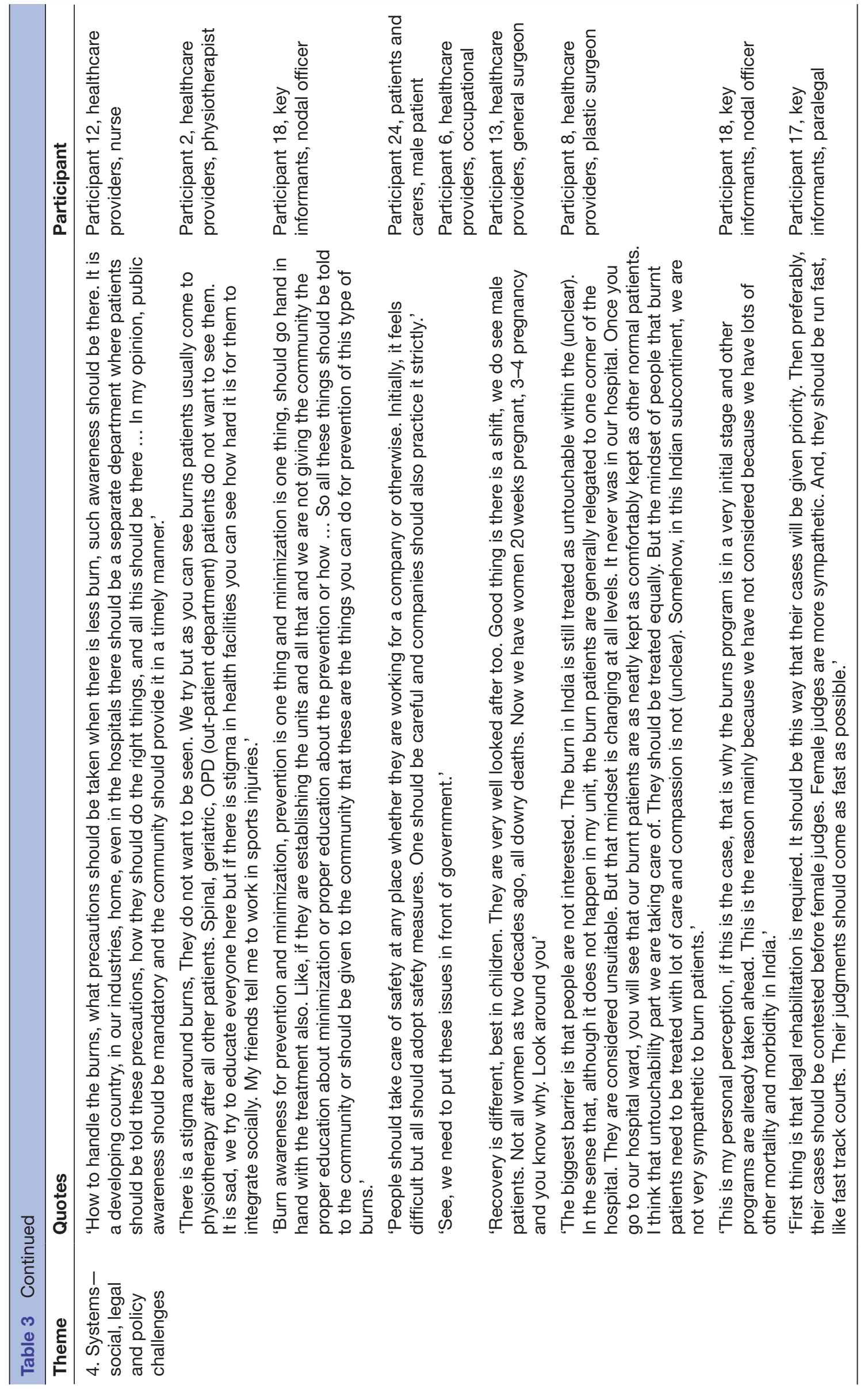


to issues around understanding the need, as well as cost and convenience. Large gaps in follow-up after discharge therefore exist (table 3 , theme 3 ). This intersects with the gap in self-care after discharge. Education around the importance of continued care is regarded as important. The most significant barrier to care is the cost (and inconvenience) of commuting for rehab and follow-up care (table 3, theme 3).

\section{Theme 4: systems-social, legal and policy challenges}

This theme articulates with table 3 , theme 4 , and the complete picture of the system depicted in figure 1 .

The need for primary prevention of burns emerged as a key policy challenge. Healthcare providers further raised issues around government support and understanding of the issues, and education/knowledge translation as key policy challenges (table 3 , theme 4). For the key informants, issues around national priorities for burns, and the need for prioritisation of burns cases in the legal system were other key policy challenges (table 3, theme 4). Social challenges such as gender, lower social economic status, poor education and stigma were identified. Health systems challenges of limited resources, out-of-pocket expenses also exist. These participants stressed that government support is needed to achieve outcomes around these aspects. Broader systems challenge of interpersonal violence, navigating the judicial systems, vocational training were the challenges raised by a range of stakeholders. This may be especially pertinent for survivors of burns as a result of gender-based violence where their support network is in jeopardy.

\section{Integrating this research with the broader context of burns, policy} and health systems in India

Based on the emergent themes above, and the interrelationship between key factors and stakeholders, figure 1 shows four key gaps that emerged out of the context of providing care and improving outcomes for burns survivors in India:

1. a structural gap, referring to discrepancies in terms of satisfaction of fundamental rights - access to healthcare;

2. a participation gap, referring to inhibitors to genuine participation in society-right and access to work, healthcare;

3. a feeling/aptitude gap, referring to psychological and social traumas, shame and mistrust;

4. a knowledge gap, referring to limited knowledge on, for example, communication- health/administrative regulations.

In the context of strengthening health systems, figure 1 therefore elicits opportunities for improvement around supply chain system design (efficiency, agility, resilience, responsiveness, execution), last mile availability (infrastructure and processes), resource mobilisation and supply chain operations financing (sufficient funding and distribution), governance and accountability (formal and informal incentives in the public health supply chain) and sustainable human capacity (developing, attracting and sustaining staff). ${ }^{17}$

It is evident from this study that care and rehabilitation services for burns survivors in India do not exist in isolation; rather, they play an integral role within the healthcare continuum and therefore must be considered within the context of the overarching health system and cultural context. People's behaviour and experiences in this healthcare system can be explained by social, economic, cultural, psychological and environmental factors, which impacts on service-seeking behaviour, adherence to treatment and the broader sociocultural influencers.

Functioning of an effective health system can strengthen the capabilities of individuals and social groups, for example, by including people in identifying health priorities and planning services from individual care to community health interventions. People-centred health systems, in this way, reflect a progressive shift that has moved thinking beyond building-blocks models of health systems towards ones that centralise a human and relational nature. These approaches can also generate preferential gains for socially disadvantaged groups, either by impacting on the structural factors that disadvantage them (women's autonomy) or by strengthening their ability to claim health resources or implement health action.

However, in practice, severe bottlenecks in accessing government healthcare services compel households to seek private care, often resulting in high out-of-pocket payments. Significant inequalities with respect to healthcare access and health outcomes exist between states, rural and urban areas, socioeconomic groups, castes and genders. Past decades have seen several initiatives targeted at improving primary healthcare systems; however, the focus has been on infectious conditions and maternal and child health.

Systems thinking approaches ${ }^{1213}$ provide guidance on where to collect more data, or to raise new questions, hypotheses, obtain buy-in from key stakeholders and develop interventions that are pragmatic. A frustration for health planners and researchers has been the aspiration that interventions shown to be effective in a research setting cannot be simply replicated at large scale or to reach populations that are most vulnerable. Therefore, this research was conceptualised with the aim of eliciting a range of priority policy considerations and future research questions from a local, setting-specific and contextualised perspective. These are presented in box 1 .

\section{LIMITATIONS}

Qualitative inquiry is time and context dependent. Therefore, this study is bound by the experiences and beliefs of these participants alone, but does resonate with what is known about the larger context. Furthermore, it was not possible to elicit relationships between the themes and the specific outcomes, although this is clearly an important area for further research. As the aim of this study was to provide considerations for future research, the method 
Box 1 Priority policy issues and future research questions: improving burns care in India

\section{Documenting the burden and recovery outcomes among burn survivors}

- Scoping burns registry to document burden and improve pathways for care for better recovery outcomes.

- How can health-related quality of life for burns survivors in India (low-and-middle-income countries) best be understood and meaningfully captured? How can the outcomes for burns survivors be improved as they move through the health system?

- How can we evaluate the financial impact/financial disability among survivors of burn injury?

\section{Quality improvement in care, equity and access in burns care}

- Need for development of best practice guidelines which include rehabilitation prescription facilitating continuum of care for improved recovery outcomes.

- How can communication about patient care throughout their flow through the healthcare system and into community-and/or self-care be enhanced? What are the best options for improved knowledge translation?

- Focus on implementation research using real-world scenarios

- Is there scope for mobile or digital health technologies to improve patient care throughout the healthcare system? What technologies exist? How can these be harnessed?

- Can (or should) task shifting to caregivers and family carers be formally included in a person-centred healthcare system? If so, how is this best achieved? What can be the pathways, family-centred care or by enabling community health worker?

- Adopting policy changes on health insurance and universal health coverage to address these challenges.

\section{Systems approach to reducing burn injury-related burden}

- Develop a systems framework for burn care and prevention using the WHO system building blocks incorporating systems organisation, networks, dynamics and knowledge.

- What is the current state of legal and financial support available for burns survivors? How is this communicated and administered? What steps can be taken to improve this process, particularly in the context of culturally sensitive issues around burns survivors such as gender-based violence?

was appropriate to eliciting rich information in this regard. Limitations around conducting research in an LMIC setting, including cultural and language barriers, are also acknowledged, and the research approach aimed to minimise this. As reported, interviews and FGDs were undertaken in Hindi and Marathi, and were jointly translated and transcribed by the interviewing researcher and the translator, and a member of the research team checked the translated transcripts with the Hindi and Marathi transcripts.

\section{CONCLUSION}

The 'invisible face of burns' is a critical public health problem in India. ${ }^{21}$ A goal of this study was to feed into the future development of pathways of care for burns survivors using a systems thinking approach ${ }^{12}{ }^{13}$ in a realist context. ${ }^{22}$ This research will enable development of acceptable models of healthcare that can then be developed and piloted in the next stage of the research process. Better understanding how and where to potentially influence optimal long-term recovery outcomes, including a return to activities of daily life and quality of life, through considerations of opportunities and gaps is a key contribution of this research.

\section{Author affiliations}

${ }^{1}$ The George Institute for Global Health, New Delhi, India

${ }^{2}$ Injury Division, The George Institute for Global Health, University of New South Wales, Sydney, New South Wales, Australia

${ }^{3}$ Faculty of Health, Federation University Australia, Ballarat, Victoria, Australia

${ }^{4}$ Choithram Hospital and Research Centre, Indore, Madhya Pradesh, India

${ }^{5}$ Centre for Global Burn Injury Policy \& Research, Swansea University, Swansea, UK

Contributors JJ and RI conceived the study and its design. JJ led data collection and data analysis. SB contributed to data analysis. SC and TP contributed to study design and assisted with study site identification and the recruitment of participants. All authors were involved in the interpretation of findings and approve this final version of the manuscript. JJ and SB drafted the manuscript.

Funding This work was funded by WH0; Geneva reference number WCCPRD3608471 2015/572126

Competing interests None declared.

Patient consent Obtained.

Ethics approval The University of Sydney Human Research Ethics Committee approved this study, with governance approvals as needed for sites.

Provenance and peer review Not commissioned; externally peer reviewed.

Data sharing statement The data collected and analysed through the current study are available from the corresponding author on reasonable request.

Open Access This is an Open Access article distributed in accordance with the Creative Commons Attribution Non Commercial (CC BY-NC 4.0) license, which permits others to distribute, remix, adapt, build upon this work non-commercially, and license their derivative works on different terms, provided the original work is properly cited and the use is non-commercial. See: http://creativecommons.org/ licenses/by-nc/4.0/

(C) Article author(s) (or their employer(s) unless otherwise stated in the text of the article) 2018. All rights reserved. No commercial use is permitted unless otherwise expressly granted.

\section{REFERENCES}

1. World Health Organisation. Burns factsheet. 2016 http://www.who. int/mediacentre/factsheets/fs365/en/ (accessed 26 Jun 2017).

2. Feigin V. GBD 2015 Mortality and Causes of Death Collaborators. Global, regional, and national life expectancy, all-cause mortality, and cause-specific mortality for 249 causes of death, 1980-2015: a systematic analysis for the Global Burden of Disease Study 2015. Lancet 2016;388:1459-544.

3. Haagsma JA, Graetz N, Bolliger I, et al. The global burden of injury: incidence, mortality, disability-adjusted life years and time trends from the Global Burden of Disease study 2013. Inj Prev 2016;22:3-18.

4. Sachs JD, McArthur JW. The Millennium Project: a plan for meeting the Millennium Development Goals. Lancet 2005;365:347-53.

5. Griggs D, Stafford-Smith M, Gaffney O, et al. Policy: sustainable development goals for people and planet. Nature 2013;495:305-7.

6. In: Mock C, Peck M, Peden M, Krug E, et al; eds. A WHO plan for burn prevention and care. Geneva: World Health Organization, 2008.

7. Sanghavi P, Bhalla K, Das V. Fire-related deaths in India in 2001: a retrospective analysis of data. Lancet 2009;373:1282-8.

8. Parray A, Ashraf M, Sharma R, et al. Burns in Jammu: retrospective analysis from a regional centre. Current Medicine Research and Practice 2015;5:55-61.

9. Peck MD. Epidemiology of burns throughout the world. Part I: distribution and risk factors. Burns 2011;37:1087-100. 
10. Van Loey NEE, Van Son MJM. Psychopathology and psychological problems in patients with burn scars. Am J Clin Dermatol 2003;4:245-72

11. Herndon DN. Total burn care: Elsevier Health Sciences, 2007.

12. Peters $\mathrm{DH}$. The application of systems thinking in health: why use systems thinking? Health Res Policy Syst 2014;12:1-6.

13. Bishai D, Paina L, Li Q, et al. Advancing the application of systems thinking in health: why cure crowds out prevention. Health Res Policy Syst 2014;12:1-12.

14. Creswell JW. Research Design: Qualitative, Quantitative, and Mixed Methods Approaches. 3rd edn. Thousand Oaks: Sage, 2009.

15. Ministry of Health and Family Welfare, Department of Health \& Family Welfare. Ministry of Health \& Family Welfare, Government of India. 2014. updated 5 May 2016. http://mohfw.gov.in/index.php

16. Gupta JL, Makhija LK, Bajaj SP. National programme for prevention of burn injuries. Indian J Plast Surg 2010;43:S6-S10.
17. Hennink MM, Kaiser BN, Marconi VC. Code saturation versus meaning saturation: how many interviews are enough? Qual Health Res 2017;27:591-608.

18. Yadav P. Health product supply chains in developing countries: diagnosis of the root causes of underperformance and an agenda for reform. Health Systems \& Reform 2015;1:142-54.

19. Kornhaber R, Rickard G, McLean L, et al. Burn care and rehabilitation in Australia: health professionals' perspectives. Disabil Rehabil 2017:1-6.

20. Morgan R, George A, Ssali S, et al. How to do (or not to do).. gender analysis in health systems research. Health Policy Plan 2016;31:1069-78.

21. Bhate-Deosthali $P$, Roy N. The invisible face of burns in India. Current Medicine Research and Practice 2015;5:53-4.

22. Pawson R, Tilley N. An introduction to scientific realist evaluation. London: Sage, 1997. 